Financial Conduct Authority

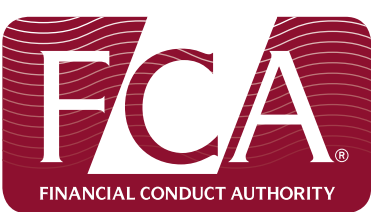

\title{
Regulatory sandbox
}

November 2015

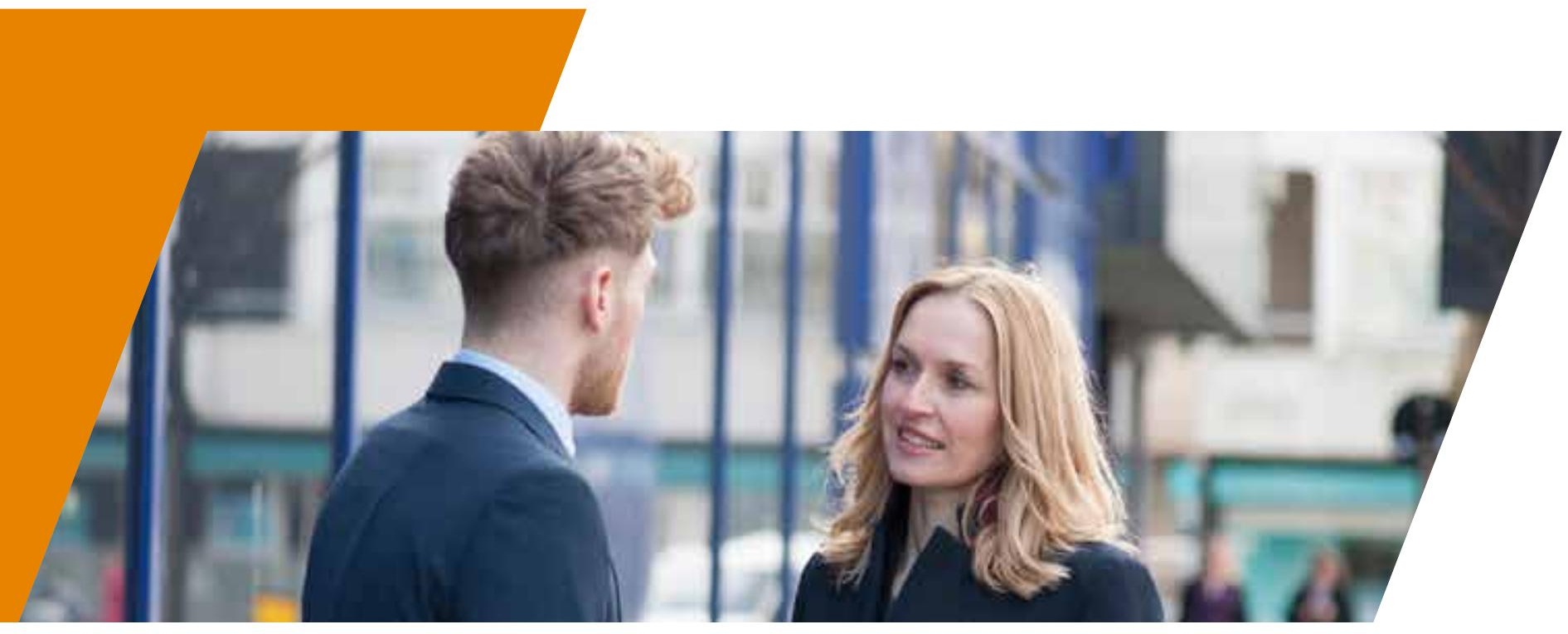




\section{Contents}

Foreword 1

1 Overview 2

2 Why introduce a regulatory sandbox? 5

3 Implementing a regulatory sandbox 7

4 Recommendations for industry 12

5 Options that require legislative change $\quad 14$

6 Next steps 16

$\begin{array}{ll}\text { Appendix } & 17\end{array}$

1 Main benefits, risks and limitations of FCA options for sandbox 17

$\begin{array}{ll}\text { Appendix } & 19\end{array}$

2 Main benefits, risks and limitations of options that industry could deliver

Appendix

20

3 Main benefits, risks and limitations of options that require legislative change

Appendix

$4 \quad$ Customer protection approaches 


\section{Foreword}

This paper marks an important milestone for the FCA: one year since the Innovation Hub opened for business.

Project Innovate was developed by the FCA to foster competition and growth in financial services by supporting both small and large businesses that are developing products and services that could genuinely improve consumers' experience and outcomes. We are proud of our achievements. Among other things, in our first year we have:

- helped over 175 innovative businesses; 5 new businesses have now been authorised

- introduced 'informal steers' that have enabled us to be more direct with firms

- worked with the Government on its plans to introduce regulation for digital currencies

- provided support to innovators by making clear our view on disproportionate de-risking that denies businesses access to banking facilities

- published a Call for Input on barriers to innovation in digital and mobile solutions

- hosted a forum to discuss 'robo-advice', and

- launched our plans for broadening and strengthening Project Innovate

This paper is a report to Her Majesty's Treasury on the feasibility and practicalities of developing a regulatory sandbox that is a 'safe space' in which businesses can test innovative products, services, business models and delivery mechanisms without immediately incurring all the normal regulatory consequences of engaging in the activity in question. We believe there is opportunity to expand Project Innovate and introduce a regulatory sandbox. In this report, we set out our plans for implementing the sandbox and proposals for how we can work with industry and the Government to further support businesses.

We are hosting an event in December to discuss the FCA's plans for implementing the sandbox and to start a conversation about our proposals for working with industry. So, we would encourage innovative businesses, trade bodies, accelerators, consumer groups and other stakeholders keen on being part of the development of a sandbox to get involved and participate in our event. 


\section{Overview}

\section{Introduction}

1.1 The FCA is committed to promoting effective competition in regulated financial services in the interests of consumers. Disruptive innovation is a key part of effective competition, which is why we launched Project Innovate. Project Innovate aims to support innovation that offers new products and services to customers and challenges existing business models. To do this, we engage constructively with innovative businesses, and seek to remove unnecessary regulatory barriers to innovation.

1.2 Following recommendations by the Government Office for Science', the FCA was asked by Her Majesty's Treasury (HMT) to investigate the feasibility of developing a regulatory sandbox for financial services. A regulatory sandbox is a 'safe space' in which businesses can test innovative products, services, business models and delivery mechanisms without immediately incurring all the normal regulatory consequences of engaging in the activity in question.

\section{Case study no 1}

The FCA recently hosted a forum to discuss automatic advice business models (roboadvice). The attendees noted that it would be very helpful if they could test their algorithms in a regulatory sandbox.

A sandbox could allow a firm to make their advice platform available to a limited number of consumers. As a safeguard, once the advice is issued, but before transactions are executed, financial advisers would review the advice. This would allow firms to learn how consumers interact with their advice platform and how their algorithm performs compared to human assessment.

1.3 A regulatory sandbox has the potential to deliver more effective competition in the interests of consumers by:

- reducing the time and, potentially, the cost of getting innovative ideas to market

- enabling greater access to finance for innovators

- enabling more products to be tested and, thus, potentially introduced to the market, and

FinTech Futures, Government Office for Science, 2015, available at: https://www.gov.uk/government/uploads/system/uploads/attachment_data/file/413095/gs-15-3-fintech-futures.pdf. 
- allowing the FCA to work with innovators to ensure that appropriate consumer protection safeguards are built in to their new products and services

1.4 We have considered three key questions when investigating the feasibility of a regulatory sandbox:

- Barriers - what regulatory barriers do firms face when testing out new ideas? How and to what extent can they be lowered?

- Safeguards - what safeguards should be in place to ensure consumers and the financial system are appropriately protected during testing?

- Legal framework - what regulatory arrangements are mandated by EU legislation and therefore are not within the gift of the FCA to change?

1.5 We believe that it is feasible for the FCA to reduce some of the existing regulatory barriers to firms that are testing new ideas, while also maintaining suitable safeguards. Where the FCA is constrained, we believe solutions are available to industry. There may also be some scope for the Government to consider changes to the legislation that regulates financial services (see Chapter 5 for more details).

1.6 This report sets out the FCA's recommendations for implementing the regulatory sandbox:

- The FCA will expand Project Innovate to include a sandbox unit: This team will be responsible for considering sandbox applications and monitoring the testing process.

- There will be eligibility criteria for access to the sandbox: The sandbox unit will use consistent criteria to decide which sandbox proposals should be accepted for testing in this framework (see section 3.4).

- The FCA sandbox unit will offer a range of options: Firms face different regulatory challenges depending on a range of factors, including regulatory status and type of activity. We have identified a range of available options for helping firms to address some of these challenges while testing in the sandbox (see section 3.5 and following).

- The regulatory sandbox should be flexible: Safeguards for consumers and the financial system while testing will be agreed between the businesses and the FCA on a case-bycase basis. This way we can ensure that protections are sufficient but at the same time not unnecessarily burdensome on the businesses considering their sandbox activities (see section 3.14 and following).

- We will work with industry to support the development of an industry led virtual sandbox: A virtual sandbox is an environment that enables firms to test their products and services in a virtual space without entering the real market (for example, by testing with publicly available data sets, or with data provided by other firms through the virtual sandbox). We propose to facilitate collaboration between interested parties and provide support when the virtual sandbox is being developed. We will look into providing access to our various systems and to some data sets (see section 4.3).

- Private-sector stakeholders acting together should consider setting up a not-forprofit sandbox umbrella company: This company could seek authorisation from the FCA and then allow innovative businesses to act as 'appointed representatives' for the duration 
of the trial in question. The FCA would help with setting up the umbrella and provide ongoing support and advice (see section 4.7).

- The Government may wish to consider whether changes to legislation may be appropriate (see Chapter 5).

1.7 The remaining chapters of this document are as follows:

- Chapter 2 sets out the benefits of introducing a sandbox

- Chapter 3 describes how a sandbox could be implemented by the FCA

- Chapter $\mathbf{4}$ makes recommendations for the industry to consider

- Chapter 5 sets out some options for legislative change for the Government to consider, and

- Chapter 6 outlines next steps

\section{Who should read this paper?}

1.8 This paper will be of particular interest to businesses looking to develop innovative ways to provide financial services. This includes, but is not limited to, innovator firms (both authorised firms and new entrants), accelerators, software firms, and technology companies. It will also be interesting to their representative bodies, and to professional firms providing support to such businesses.

\section{Is this of interest to consumers?}

1.9 This report will be interesting to consumers who want to engage with new solutions to manage their financial affairs and consumer groups who represent their interests. This report describes the different ways that consumers can participate in testing and what consumer protection will be available.

\section{What will we do next?}

1.10 We intend to open the sandbox unit for testing proposals in spring 2016. Over the course of the next few months we will engage with interested parties to finalise the design of how the unit will operate. As part of this engagement process we have arranged an event in December 2015. Please see https://innovate.fca.org.uk/ for more information.

1.11 We will also start engaging with stakeholders regarding establishing a virtual sandbox and a sandbox umbrella.

1.12 We have set up an e-mail address sandbox@fca.org.uk for anyone who would like to provide input into the development of the sandbox unit. 


\section{2.}

\section{Why introduce a regulatory sandbox?}

2.1 In this chapter we set out the potential benefits of introducing the regulatory sandbox.

2.2 The FCA wants to promote competition by supporting disruptive innovation. It is estimated that the UK's FinTech sector generates about $f 20$ bn in revenue annually, with a total market of $\mathrm{f3} .6 \mathrm{bn}$ in 'disruptive' FinTech (small, innovative firms disintermediating incumbent financial services firms with new technology). ${ }^{2}$ Half of the promising 'disruptive' FinTech start-ups in Europe are in the UK. ${ }^{3}$ To remain Europe's leading FinTech Hub, we have to ensure that we continue to be an attractive market with an appropriate regulatory framework.

2.3 The potential benefits of a regulatory sandbox could be significant from:

- Reduced time-to-market at potentially lower cost: Delays driven by regulatory uncertainty disproportionately affect first-movers and discourage innovators. Evidence from other industries suggests that time-to-market can be increased by about a third in this way, at a cost of about $8 \%$ of product lifetime revenue. ${ }^{4}$

- Better access to finance: Financial innovation relies on investment, much of it through equity funding. Regulatory uncertainty at a crucial growth stage means that FinTech firms find it harder to raise funds and achieve lower valuations as investors try to factor in risks that they are not well placed to assess. Evidence from other industries suggests valuations may be reduced by about $15 \%$ due to regulatory uncertainty ${ }^{5}$; it is more difficult to estimate the number of firms that fail to achieve any funding at all.

- More innovative products reaching the market: Due to regulatory uncertainty, some innovations are abandoned at an early stage and never even tested. As the sandbox framework enables firms to manage regulatory risks during the testing stage, more solutions may be trialled and later potentially introduced to the market.

2.4 The benefits the sandbox could provide firms should lead to better outcomes for consumers through, for example, an increased range of products and services, reduced costs, and improved access to financial services.

2.5 The sandbox enables the FCA to work with innovators to ensure that appropriate consumer protection safeguards are built in to their new products and services before these reach a mass market.

2 Landscaping UK FinTech, Ernst \& Young, 2014, available at: https://www.gov.uk/government/uploads/system/uploads/attachment_data/file/341336/Landscaping_UK_Fintech.pdf (EY 2014). 3 EY 2014

4 Stern, Ariel Dora, Innovation under regulatory uncertainty: Evidence from medical technology, Harvard University, 2014, available at: http://www.rotman.utoronto.ca/-/media/Files/Programs-and-Areas/Strategy/papers/JMP_Stern_Jan_2014.pdf.

5 In the face of uncertainty: A challenging future for biopharmaceutical innovation, Deloitte, 2014, available at: http://www2.deloitte.com/content/dam/Deloitte/lu/Documents/life-sciences-health-care/us_consulting_Inthefaceofuncertainty_040614.pdf. 
2.6 Since the sandbox is intended for testing new solutions, in real life situations, the risk of consumer detriment needs to be carefully considered, as does the need to respect binding legal rules. These constraints will limit the flexibility the FCA can offer. However, even with these limits, we believe that it is feasible to develop a sandbox that will be helpful for innovative firms and deliver the above benefits. 


\section{3. \\ Implementing a regulatory sandbox}

3.1 In this chapter we set out our plans for implementing a regulatory sandbox: the criteria we plan to use, the options we have available, our approach to safeguards, and the 'firm journey'.

3.2 For dual regulated firms, we will work with the Prudential Regulation Authority (PRA) to agree on the appropriate sandbox options. Where necessary, these will be delivered in consultation or with the consent of the PRA under the current terms of the Memorandum of Understanding in place between the FCA and the PRA, or under the relevant provisions of the Financial Services and Markets Act 2000 (FSMA). For example, the FCA will consult with the PRA in respect of restrictions or rule waivers applied to dual regulated firms.

\section{Criteria for using sandbox}

3.3 Introducing publicly available criteria that need to be met as a prerequisite for entry into the sandbox will help to ensure that we treat all businesses fairly and transparently, while also ensuring we focus on propositions that are genuinely of benefit to consumers.

3.4 We recommend that the sandbox criteria is similar to the criteria for requesting support from the FCA's Innovation Hub:

- Is the firm in scope: Is the planned new solution designed for or supports the financial services industry?

- Genuine innovation: Is the new solution novel or significantly different to existing offerings?

- Consumer benefit: Does the innovation offer a good prospect of identifiable benefit to consumers? This criterion should continue to be met throughout the period of sandbox testing.

- Need for sandbox: What is the objective of testing? Does the business have a genuine need for testing within the sandbox framework?

- Background research: Has the business invested appropriate resources in developing the new solution, understanding the applicable regulations, and mitigating the risks? 


\section{FCA options for sandbox}

3.5 We engaged with firms, trade bodies and other stakeholders to understand what a sandbox could deliver to be a useful facility for innovative businesses. What we found was that innovators face different challenges depending on a range of factors, including whether they are authorised and what kind of products/services they want to test.

3.6 Authorised firms and technology firms that provide outsourced services to such firms are mainly concerned about the FCA's reaction to new solutions. They are interested in early dialogue, clarity about how to apply rules and the risk of the FCA taking enforcement action at a later date. Unauthorised firms have to incur potentially significant one-off costs and apply for authorisation before they can meaningfully explore consumers' appetite for a product/service or if there are any significant risks posed to consumers.

3.7 We have identified a number of options that the FCA can use to address some of these challenges while firms test out their ideas in the sandbox.

\section{Option for unauthorised firms}

3.8 We will set up a tailored authorisation process, similar to the banking mobilisation authorisation process ${ }^{6}$, to allow testing by firms who need to become authorised to trial their new products or services. Sandbox firms will first be authorised with restrictions, allowing them to test their ideas but no more (restricted authorisation). Once the firm is able to meet 'full' requirements, restrictions can be lifted.

3.9 The restricted authorisation option will allow firms to become authorised in their own right while only having to meet authorisation requirements that are proportionate to testing activities. This process should also be quicker than applying for a 'full' authorisation. When launching full commercial activity, firms will have to apply to have restrictions lifted in order to carry on relevant regulated activities but they will not have to apply for new authorisation.

3.10 This option does have some limitations. Before being able to test, firms still need to become authorised and meet relevant requirements which requires time and resource. Further, EU legislation restricts the flexibility that the FCA has in setting some authorisation requirements (see section 5.5. for an illustrative list of firms that need to be authorised or registered under EU legislation). These requirements may be quite onerous for firms (especially for start-ups). For such firms, we have suggested that the sandbox umbrella option may be a more appropriate option to address the challenges they face in taking innovative products/services to market (see section 4.7).

3.11 A restricted authorisation and sandbox umbrella will not apply to carrying out activities outside the FSMA: e.g. payment services and e-money. The Payment Services Regulations and Electronic Money Regulations already provide for a lighter registration regime for small payment institutions and small e-money firms and a number of exemptions when these regulations do not apply (e.g. limited network).

3.12 For avoidance of doubt, this restricted authorisation option under the sandbox framework will not replace the banking mobilisation authorisation process or extend it to other firms. This option will not be an alternative route for authorisation for all firms. We will only use it to enable firms who meet the sandbox eligibility criteria to test their new products and services.

$6 \overline{\text { This process is described }}$ as Option B in the Banking Authorisation Process, January 2014. 


\section{Options for authorised firms and outsourcing arrangements}

3.13 Authorised firms and technology firms that provide outsourced services to such firms are mainly concerned about the FCA's reaction to new solutions. The following options help to manage this risk by giving certainty that the FCA will not take enforcement action at a later date in relation to testing activities, provided firms abide by the conditions agreed with the sandbox unit. These options may also be used by technology companies when they find authorised firms that are interested in testing their products or services.

- No enforcement action letters (NALs): We could issue a NAL stating that no FCA enforcement action will be taken against testing activities where we are reasonably satisfied that the activities do not breach our requirements or harm our objectives. We think it would be appropriate for the FCA to reserve the right to close the trial. The FCA's commitment not to take enforcement action applies to the period from the issue of the NAL until the testing is completed or closed by the FCA. The US Consumer Financial Protection Bureau (CFPB) is implementing a similar policy. ${ }^{7}$

It is important to note that this only addresses the risk of enforcement action by the FCA and does not limit businesses' liability towards their customers.

- Individual Guidance (IG): In addition to NALs, the FCA can issue individual guidance to a firm on the interpretation of applicable rules in respect of testing activities the firm may be carrying out. If the firm acts in accordance with this guidance, it will give them certainty that the FCA would not take action against them.

- Waivers: Where it is clear that testing activities do not meet our rules but the firm can meet the waiver test ${ }^{8}$ and the rules are within the FCA's power to waive, the FCA can waive or modify particular rules for sandbox firms. A waiver or modification would allow what would otherwise be a temporary breach of our rules. The FCA is limited in what it can waive by EU legislative requirements. This is not an option for firms not regulated under FSMA (e.g. payment institutions).

\section{Safeguards}

3.14 We believe that the benefits that the sandbox can bring to firms should lead to better outcomes for consumers through, for example, an increased range of products and services, reduced cost, and improved access to financial services. However, there is potential for customer detriment when innovative financial products or services are tested in real life situations. This risk needs to be carefully managed.

3.15 There are a number of approaches that the FCA can take to protect customers that participate in sandbox testing (Appendix 4 sets this out in more detail):

- Approach 1: As in clinical trials, sandbox firms can only test their new solutions on customers who have given informed consent to be included in testing. Customers are notified of the potential risks and the available compensation.

7 For more detail on the CFPB's No Action Letters policy see:

https://www.federalregister.gov/articles/2014/10/16/2014-24645/policy-on-no-action-letters.

8 Under section 138A(4) of FSMA, the FCA may not give waivers or modifications unless we are satisfied that:

- compliance by the person with the rules, or with the rules as unmodified, would be unduly burdensome or would not achieve the purpose for which the rules were made, and

- the waiver or modification would not adversely affect the advancement of any of the FCA's objectives. 
- Approach 2: FCA agrees on a case-by-case basis the disclosure, protection and compensation appropriate to the testing activity.

- Approach 3: Customers have the same rights as customers who engage with other authorised firms (e.g. complain to firm, then to the Financial Ombudsman Service (FOS), and have access to the Financial Services Compensation Scheme (FSCS) if a firm fails).

- Approach 4: Businesses undertaking sandbox trials are required to compensate any losses (including investment losses) to customers and must demonstrate that they have the resources (capital) to do that.

3.16 It is important that the safeguards for customers are appropriate to the sandboxing activity. So we prefer approach 2 - the FCA agrees on safeguard proposals on a case-by-case basis (for example, these could be approach 1, 3, or 4 alone or accompanied by some other safeguards). This approach enables flexibility in setting appropriate customer protection for the testing activities.

\section{Case study no 2}

For testing blockchain based transaction tools, the appropriate safeguards may be limiting testing only to sophisticated customers, using approach 1 , and daily monitoring of whether the transactions are executed correctly and on time.

3.17 With the proposed tools for sandbox, consumers will have FOS and FSCS protection ${ }^{9}$, provided that the tested solutions fall within their jurisdiction.

3.18 The parameters of the sandbox activities will have to take into account that testing should not cause risks to the financial system (i.e. scale of testing has to be limited).

9 In case of waivers, FSCS cover is available if there is also a breach of general law requirements (e.g. negligence, misrepresentation). Waivers could affect FOS assessment if the firm otherwise acted in accordance with its obligations, and fairly and reasonably. 


\section{Firm journey for FCA options}

3.19 The exact firm journey and the FCA's involvement will depend on the specific options used, the regulatory status of the firm, the solution being tested and the extent of consumer involvement. The below chart 1 is an outline of the 'firm journey' for options that can be implemented by the FCA.

\section{Chart 1 - Firm journey}

Criteria are introduced as a prerequisite for sandbox to ensure consistent treatment of firms and advancement of FCA objectives.

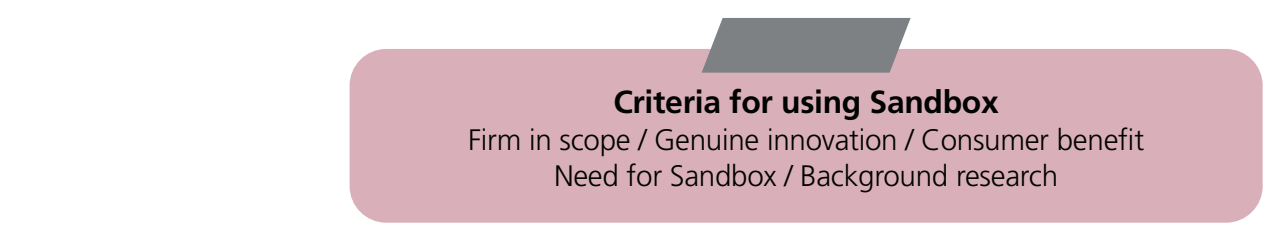

(1)

Firm proposal to use sandbox

A firm submits a testing proposal to the FCA setting out

the new solution and how it meets the criteria.

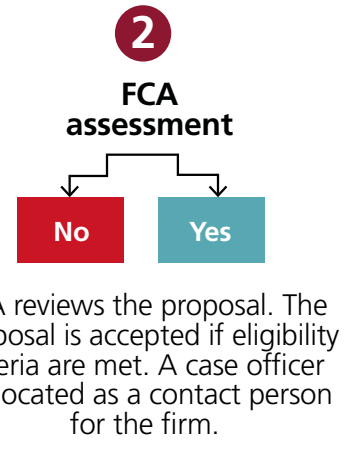

6

Firm decides whether it will offer solution

After the FCA receives and reviews the final report, the firm decides whether it will offer the new solution outside the sandbox. proposal is accepted if eligibility criteria are met. A case officer is allocated as a contact
for the firm.

\section{5}

Testing and monitoring

The firm starts testing and engages with the FCA according to what was agreed in step 3.

\section{3}

Firm and FCA collaborate and agree a testing approach

If the proposal is accepted, the FCA works with the firm to establish the best sandbox option, testing parameters, measures for outcomes, reporting requirements and safeguards.

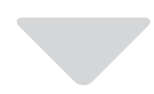

\section{Firm submits \\ $\downarrow$ \\ FCA reviews \\ final report}

The firm submits a final report about the outcomes of testing and the FCA reviews the report.
4.

Delivery of sandbox option

FCA allows the firm to start testing. 


\section{4. \\ Recommendations for industry}

4.1 In this chapter we set out the solutions that can be delivered by industry acting collectively (e.g. financial services firms, software developers, technology companies, accelerators, and so on) to help address the challenges that innovators face when taking a new product or service to market.

4.2 In addition to the options that the FCA has, we think there are also solutions that the industry can implement which offer more flexibility. We think there is a potential role for trade bodies in bringing together industry to achieve these solutions.

\section{Virtual sandbox}

4.3 A virtual sandbox could be introduced by industry. This would be an environment to enable firms to test their solutions virtually without entering the real market. A number of large firms already have similar solutions for testing technologies but we understand these operate separately from each other and with data only from the owners of these sandboxes.

4.4 The virtual sandbox could be, for example, a cloud-based solution set up and equipped in collaboration between the industry, which businesses then could customise for their products or services, run tests with public data sets or data provided by other firms through the virtual sandbox, and then invite firms or even consumers to try their new solution. In this environment, there is no risk of consumer detriment, risk to market integrity or financial stability while testing.

4.5 A virtual sandbox could be used by all innovators regardless of whether they are authorised or not. It will probably be most useful for small start-ups who cannot build their own sandboxes. Technology companies seeking to engage with incumbents may also benefit; being accepted into a virtual sandbox may encourage more incumbents to engage with the new solution. This environment could also allow collaboration between a number of businesses and other interested parties (e.g. academia) to develop innovative solutions quicker and in a more informed way.

4.6 We do not think it is necessary for the FCA to set up the virtual sandbox; the industry is well placed to set up a useful virtual testing environment itself. However, we propose to facilitate collaboration between interested parties and provide support when the virtual sandbox is being developed. We will look into providing access to our various systems and to some data sets (provided this does not breach requirements from the Data Protection Act 1998 or section 348 of FSMA). We would be interested in having access to the results of the virtual sandboxing activity. 


\section{Case study no 3}

The FCA has committed to identifying ways to support the adoption of technologies that facilitate compliance with regulatory requirements (RegTech). Any products developed to address this challenge could be tested in the virtual sandbox and developed further in collaboration between interested parties.

\section{Sandbox umbrella}

4.7 A not-for-profit company could be set up by industry to act as a sandbox umbrella that allows unauthorised innovators to offer their services under its shelter as appointed representatives. The umbrella company would need to be authorised with appropriate permissions and then supervised by the FCA as other authorised firms. The umbrella company would monitor its appointed representatives.

4.8 This option would take some time to implement but it would be faster and simpler for innovators to use than the restricted authorisation option outlined in Chapter 3. Innovators would not have to apply for authorisation and meet authorisation requirements in their own right. The umbrella company would assess whether the firms applying to become appointed representatives are ready to test their solutions.

4.9 It is worth noting that the appointed representative regime is not available for all regulated activities, so not all innovative businesses would be able to use the sandbox umbrella. For example, this regime does not apply to insurance underwriting and managing investments ${ }^{10}$. These firms would need to use the restricted authorisation option described in Chapter 3 to participate in the sandbox.

4.10 We believe that the sandbox umbrella should be introduced by industry. An industry-led umbrella is better equipped to assess and advise sandbox firms and facilitate overall innovation. The FCA would help to set up the umbrella through the Innovation Hub and provide ongoing support and advice. We would also supervise the umbrella to ensure oversight of testing activities.

10 See the Financial Services and Markets Act 2000 (Appointed Representatives) Regulations 2001/1217 for more detail. 


\section{5. \\ Options that require legislative change}

5.1 In this chapter we set out considerations regarding whether changes to legislation that governs financial services have the potential to better address some of the challenges described above.

5.2 We have identified two potential options as feasible:

- New Regulated Activity: The Regulated Activities Order ${ }^{11}$ could be amended to introduce a new regulated activity of 'sandboxing' for testing. This option could enable the FCA to create a new sandbox regime (with new authorisation requirements and rules) that is more flexible than the current regime in areas where EU legislation does not apply or where the UK can have additional rules to those that exist under EU legislation. Thus, it could allow for a streamlined authorisation process and potentially less regulatory requirements to comply with when testing. The drawbacks to this option are that firms still need to become authorised before being able to test, and proposed changes need to take into account EU requirements. Further, this option will not apply to activities that are not regulated under FSMA (e.g. payment services and e-money). Thus, this change could have a limited effect.

- Amending the waiver test: The FCA's power to issue waivers is limited in relation to requirements which come from EU legislation and by the current waiver test provided in FSMA. The Government could consider changing the waiver conditions in FSMA to make it easier for the FCA to waive rules for a firm within the sandbox. This could be achieved by introducing a new test for sandbox firms. However, we would not be able to waive rules stemming from EU legislation despite this change.

5.3 We recommend considering these options further when we have collected more evidence about the specific needs of innovative firms during the testing of new solutions. This evidence would enable us to understand better which specific rules or legislation firms struggle with when testing innovative solutions and then analyse the effect the above legislative changes could have.

5.4 We also analysed the two potential options below:

- Amendment to Exemptions Order ${ }^{12}$ : The Exemptions Order could be amended to introduce an exemption from authorisation for sandbox firms. The exemption would apply if the firm complies with sandbox conditions and the FCA confirms that it meets sandbox criteria.

- Amendment to By Way of Business Order ${ }^{13}$ : The By Way of Business Order could be amended to provide that a sandbox activity is not to be regarded as carried out 'by way of

\footnotetext{
11 Financial Services and Markets Act 2000 (Regulated Activities) Order 2001/544.

12 Financial Services and Markets Act 2000 (Exemption) Order 2001/1201.

13 Financial Services and Markets Act 2000 (Carrying on Regulated Activities By Way of Business) Order 2001/1177.
} 
business', so it would not be a regulated activity. This would apply if the firm complies with sandbox conditions and the FCA confirms that it meets sandbox criteria.

5.5 We consider the options in section 5.4 to be unfeasible due to limitations set by EU legislative requirements. For example, subject to a range of exclusions, under a number of different pieces of EU legislation, the following firms must be authorised or registered: credit institutions, some insurance and reinsurance companies, insurance and reinsurance intermediaries, firms who provide 'investment services or activities' under MiFID, some payment institutions and e-money institutions, UCITS and their management companies, Alternative Investment Fund Managers, mortgage lenders, administrators and brokers (from 21 March 2016), and creditors. The FCA cannot exempt such firms from authorisation requirements, so amending the Exemptions Order or By Way of Business Order would have a very limited effect. 


\section{6. \\ Next steps}

6.1 We intend to open the sandbox unit for testing proposals in spring 2016. Over the course of the next few months we will engage with interested parties to design how the unit will operate. In the first year, we will trial the sandbox with a limited number of firms so we can develop the sandbox framework based on our experience.

6.2 As part of the engagement process we have arranged an event in December 2015. Please see https://innovate.fca.org.uk/ for more information. We have also set up an e-mail address sandbox@fca.org.uk for anyone who would like to provide input into the development of the sandbox unit.

6.3 We will also start engaging with stakeholders regarding establishing a virtual sandbox and a sandbox umbrella. 


\section{Appendix 1: \\ Main benefits, risks and limitations of FCA options for sandbox}

\section{Restricted authorisation}

\begin{tabular}{l|l}
\hline $\begin{array}{l}\text { Benefits } \\
\checkmark \text { Within limits of applicable EU legislation, } \\
\text { authorisation requirements (threshold } \\
\begin{array}{l}\text { conditions) are calibrated to restrictions, so } \\
\text { these are less difficult for innovators to meet }\end{array}\end{array}$ & $\begin{array}{l}\text { Risks and drawbacks } \\
x \text { Firms still need to apply for authorisation } \\
\text { before being able to test new solutions } \\
x \text { EU legislative requirements restrict flexibility } \\
\text { of authorisation requirements (e.g. capital } \\
\text { requirements) }\end{array}$ \\
$\begin{array}{l}\text { Restricted authorisation process could be } \\
\text { potentially quicker than regular process }\end{array}$ \\
$\begin{array}{l}\boldsymbol{F} \text { FOS and FSCS protection apply if activity is } \\
\text { in scope }\end{array}$ \\
$\begin{array}{l}\text { The FCA will have to create bespoke } \\
\text { authorisation requirements for each sandbox } \\
\text { investors }\end{array}$ \\
$\begin{array}{l}\text { firm, which could be resource-intensive } \\
\end{array}$
\end{tabular}

\section{No enforcement action letter (NAL)/ Individual guidance (IG)}

\begin{tabular}{|c|c|}
\hline Benefits & Risks and drawbacks \\
\hline $\begin{array}{l}\checkmark \text { NALs and IG give firms clarity and certainty } \\
\text { that the FCA will not take enforcement action } \\
\text { regarding testing activities provided they keep } \\
\text { to what is agreed }\end{array}$ & $\begin{array}{l}x \text { These will be resource-intensive, complex to } \\
\text { issue, and require disclaimers. There is a risk } \\
\text { that the necessary disclaimers may affect the } \\
\text { usefulness of these options. }\end{array}$ \\
\hline $\begin{array}{l}\checkmark \text { NALs and IG are only issued if testing activity } \\
\text { complies with relevant regulation, so the risk } \\
\text { of breaching EU requirements is minimal }\end{array}$ & \\
\hline $\begin{array}{l}\checkmark \text { FSCS and FOS protection apply if activity is in } \\
\text { scope (civil claims for damages for breach of } \\
\text { statutory duty might be hampered) }\end{array}$ & \\
\hline
\end{tabular}

14 For example, subject to various exclusions, under various pieces of EU legislation the following firms must be authorised or registered: credit institutions, some insurance and reinsurance companies, insurance and reinsurance intermediaries, firms who provide 'investment services or activities' under MiFID, some payment institutions and e-money institutions, UCITS and their management companies, Alternative Investment Fund Managers, mortgage lenders, administrators and brokers (from 21 March 2016), and creditors. 


\section{Waivers}

\section{Benefits}

$\checkmark$ This is the only option for sandbox if a rule might be breached when testing the innovative solution, thus, it adds flexibility to the regime

$\checkmark$ Waivers would enable firms to test concepts before ensuring compliance with all relevant rules (firms can start testing quicker)

$\checkmark$ Waivers give firms certainty that the FCA will not take enforcement action regarding testing activities provided they keep to what is agreed

\section{Risks and drawbacks}

$\boldsymbol{x}$ The FCA cannot waive requirements derived from EU law

$x$ The FCA's power to issue waivers is limited by the FSMA waiver test. Legislative change may be necessary to broaden the scope for waivers.

$x$ FSCS cover is available only if there is a breach of general law requirements (e.g. negligence, misrepresentation)

$x$ Waivers could affect FOS assessment if the firm otherwise acted in accordance with its obligations, and fairly and reasonably (civil claims for damages for breach of statutory duty might be hampered) 


\section{Appendix 2: \\ Main benefits, risks and limitations of options that industry could deliver}

\section{Virtual sandbox}

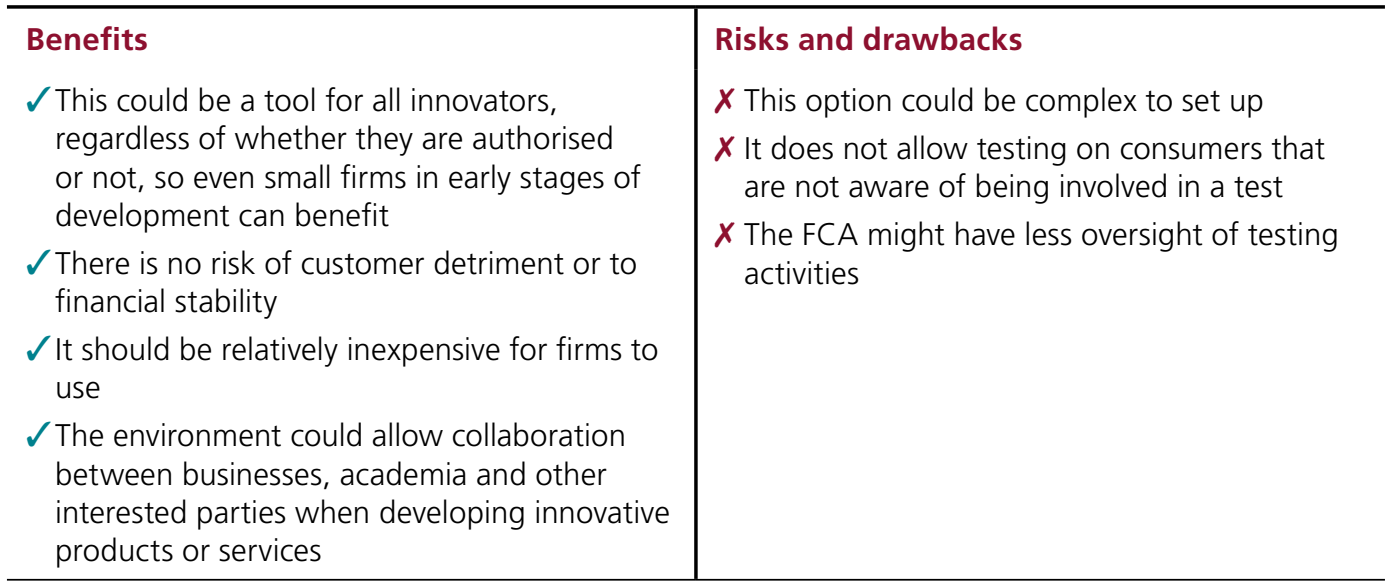

\section{Sandbox umbrella}

\begin{tabular}{|c|c|}
\hline Benefits & Risks and drawbacks \\
\hline $\begin{array}{l}\checkmark \text { It could be quicker and simpler for innovators } \\
\text { to use than restricted authorisation } \\
\text { (innovators would not have to meet } \\
\text { authorisation requirements on their own) } \\
\checkmark \text { FSCS and FOS protection apply if activity is in } \\
\text { scope } \\
\checkmark \text { EU law requirements have less impact on this } \\
\text { option than on restricted authorisation } \\
\checkmark \text { Industry is well placed to set up the umbrella } \\
\text { and monitor innovators, so innovators can } \\
\text { also be helped with commercial matters }\end{array}$ & $\begin{array}{l}x \text { This option could be complex to set up } \\
x \text { The appointed representative regime has } \\
\text { scope limitations } \\
x \text { The FCA might have less oversight of testing } \\
\text { activities }\end{array}$ \\
\hline
\end{tabular}




\section{Appendix 3: \\ Main benefits, risks and limitations of options that require legislative change}

\section{New regulated activity}

\begin{tabular}{l}
\hline Benefits \\
$\checkmark$ The FCA can create a new regime for sandbox \\
firms that is more flexible than the current \\
regime in areas where EU legislation does not \\
apply, or the UK can introduce additional rules \\
to those required under EU law \\
$\checkmark$ Authorisation (even if only for sandbox) can \\
encourage investors \\
$\checkmark$ If legislative/rules changes provide for it (e.g. \\
change in the Compensation Sourcebook \\
(COMP)), consumer rights are intact
\end{tabular}

Risks and drawbacks

$X$ Firms still need to apply for authorisation before being able to test new solutions

$x$ EU law limits the flexibility that the new regime can provide (e.g. EU law might set capital requirements)

$\boldsymbol{x}$ Legislative changes take significant time and resource to introduce

$\boldsymbol{x}$ This option will not apply to firms that are not regulated under FSMA (e.g. payment institutions and e-money firms)

\section{Broadening of the FSMA waiver test}

\begin{tabular}{l}
\hline Benefits \\
$\checkmark$ This change would help the FCA to apply the \\
waiver power more broadly, consequently \\
giving more flexibility to sandbox firms \\
$\checkmark$ The main benefits of issuing waivers are listed \\
in Appendix 1
\end{tabular}

\author{
Risks and drawbacks \\ $x$ Legislative changes take significant time and \\ resource to introduce \\ $\boldsymbol{x}$ The main risks and drawbacks of issuing \\ waivers are listed in Appendix 1
}

\section{Amendment to Exemptions Order/By Way of Business Order}

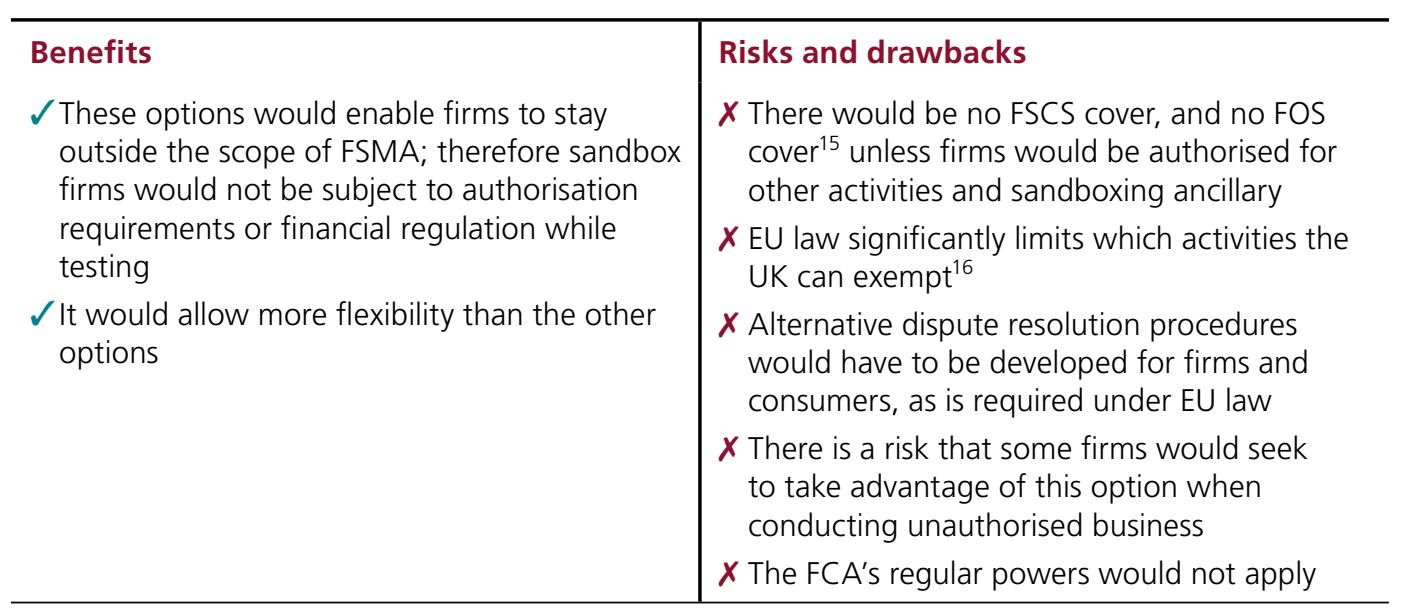

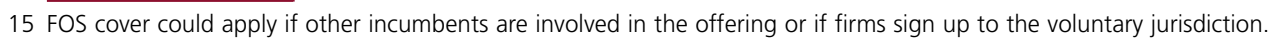




\section{Appendix 4: Customer protection approaches}

There are a number of approaches the FCA can take to protect customers that participate in sandbox testing:

Approach 1: As in clinical trials, sandbox firms can only test their new solutions on customers who have given informed consent to be included in testing. Customers are notified of the potential risks and the available compensation.

- Main benefit: Flexibility for parties to agree on compensation arrangements appropriate for particular tests.

- Main drawbacks: This would only be an option for sophisticated consumers and firms. There is a risk that less sophisticated consumers might not understand that their rights are limited and their awareness of testing will distort outcomes. Selection bias, with cautious consumers opting out of trials as they deem trials too risky, can distort testing outcomes further.

- FOS/FSCS: Consumers cannot contract out of the FSCS and may also be able to complain to the FOS.

Approach 2: Businesses seeking to use the sandbox propose what disclosure, protection, and compensation they will provide to customers, and the FCA will work with businesses to ensure that we are comfortable with what has been proposed. ${ }^{17}$

- Main benefit: Flexibility for firms to propose compensation arrangements appropriate for particular tests. If the safeguards are sufficient, testing with customers who are unaware of testing might be considered.

- Main drawbacks: If the agreed protection proves to be insufficient, there might be customer detriment.

- FOS/FSCS: If the FOS has jurisdiction, it would not have to abide by the arrangement agreed between firms and the FCA. ${ }^{18}$ Consumers cannot contract out of the FSCS.

Approach 3: Customers participating in sandbox testing have the same rights as customers who engage with other authorised firms (e.g. consumers can complain to firm, then to the FOS, and have access to the FSCS if a firm fails).

- Main benefit: The system is already in place and customers do not bear additional risks.

17 This is similar to the CFPB approach in the No Action Letters policy, for more detail on the policy see: https://www.federalregister.gov/articles/2014/10/16/2014-24645/policy-on-no-action-letters.

18 However, if a redress scheme is established under section 404F(7) of FSMA, the FCA may bind the FOS to the terms of the scheme. 
- Main drawbacks: Sandbox firms must pay the FOS and the FSCS fees, and their financial exposure is higher than just compensating losses. The sandbox umbrella has to become subject to the FOS and the FSCS for this option to apply.

- FOS/FSCS: FOS and FSCS protection apply if activity is in scope.

Approach 4: A condition for joining sandbox is that businesses undertake to compensate any losses (including investment losses) to customers and can demonstrate that they have the resources (capital) to do that.

- Main benefit: Unless firms become insolvent, customers bear no risk from transacting with sandbox firms. This is a higher level of protection than when customers engage with regular authorised firms.

- Main drawbacks: Sandbox firms bear all the risks (including investment risk) which could make the sandbox an unattractive and unaffordable option for smaller firms. Further, if customers know that they have nothing to lose, this may distort testing outcomes.

- FOS/FSCS: FOS and FSCS protection apply if activity is in scope.

Preferred approach: When assessing customer protection approaches, the FCA has to take into account our competition duty to promote effective competition. As such, despite providing the highest level of protection, approach 4 is not the preferred option as the sandbox would consequently become an unattractive tool that only larger firms with significant resources could use. For the sandbox regime to be attractive to a variety of firms, including new entrants, approach 2 would be the better choice. It would enable firms to analyse and make arrangements for appropriate customer protection for the particular test, while giving the FCA the opportunity to ensure that the safeguards are suitable (e.g. in terms of disclosure to customers and compensation arrangements). 
Financial Conduct Authority

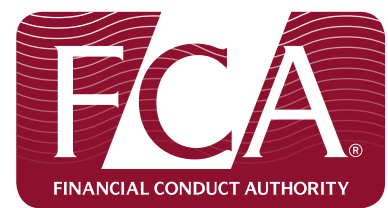

PUB REF: 005147

(C) Financial Conduct Authority 2015

25 The North Colonnade Canary Wharf London E14 5HS

Telephone: +44 (0)20 70661000

Website: www.fca.org.uk

All rights reserved 